\title{
DÜBLIN
}

Technological University Dublin

ARROW@TU Dublin

\section{Human performance in manufacturing tasks: Optimization and assessment of required workload and capabilities}

\author{
Maria Chiara Leva \\ Technological University Dublin, mariachiara.leva@tudublin.ie \\ Lorenzo Comberti \\ Politecnico di Torino, lorenzo.comberti@polito.it \\ Micaela Demichela \\ Politecnico di Torino
}

See next page for additional authors

Follow this and additional works at: https://arrow.tudublin.ie/schfsehcon

Part of the Environmental Public Health Commons, Environmental Studies Commons, Human Factors Psychology Commons, Industrial and Organizational Psychology Commons, and the Occupational Health and Industrial Hygiene Commons

\section{Recommended Citation}

Leva, Maria \& Comberti, Lorenzo \& Demichela, Micaela \& Caimo, Alberto. (2019). Human Performance in Manufacturing Tasks: Optimization and Assessment of required Workload and Capabilities. DOI: 10.3850/ 978-981-11-2724-3_0688-cd.

This Conference Paper is brought to you for free and open access by the School of Food Science and Environmental Health at ARROW@TU Dublin. It has been accepted for inclusion in Conference papers by an authorized administrator of ARROW@TU Dublin. For more information, please contact arrow.admin@tudublin.ie, aisling.coyne@tudublin.ie,gerard.connolly@tudublin.ie.

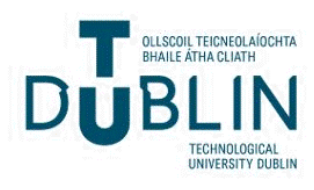


Authors

Maria Chiara Leva, Lorenzo Comberti, Micaela Demichela, and Alberto Caimo

This conference paper is available at ARROW@TU Dublin: https://arrow.tudublin.ie/schfsehcon/31 
Human performance in manufacturing tasks: optimization and assessment of required workload and capabilities

\author{
Maria Chiara Leva \\ School of Environmental Health, Technological University Dublin.E-mail: chiara.leva@,dit.ie
}

Lorenzo Comberti

DISAT, Politecnico di Torino, Italy.E-mail: lorenzo.comberti@polito.it

Micaela Demichela

DISAT, Politecnico di Torino, Italy.E-mail: lorenzo.comberti@polito.it

Alberto Caimo
School of Mathematical Sciences, Technological University Dublin.E-mail: alberto.caimo@dit.ie

This paper discusses some examples where human performance and or human error prediction was achieved by using a modified version of the Rasch model(1980), where the probability of a specified outcome is modelled as a logistic function of the difference between the person capacity and item difficulty. The model needs to be modified to take into account an outcome that may not be dichotomous and o take into account the interaction between two macro factors: (a) Task complexity: that summarises all factors contributing to physical and mental workload requirements for execution of a given operative task \& (b) Human capability: that considered the skills, training and experience of the people facing the tasks, representing a synthesis of their physical and cognitive abilities to verify whether or not they are matching the task requirements. Task complexity can be evaluated as a mathematical construct considering the compound effects of Mental Workload Demands and Physical Workload Demands associated to an operator task. Similarly, operator capability can be estimated on the basis of the operators' set of cognitive capabilities and physical conditions. The examples chosen for the application of the model were quite different: one is a set of assembly workstation in large computer manufacturing company and the other a set of workstation in the automotive sector. This paper presents and discusses the modelling hypothesis, the interim field data collection, results and possible future direction of the studies..

Keywords: Human performance, human factors, human error, workload.

\section{Introduction}

This paper presents a framework adopted to assess human error in assembly tasks in two different large manufacturing plants (Comberti et al 2019). There is growing interest in addressing Human Factors as part of these areas (Hong et al. 2007). The discipline of Human Factors in fact, has a very relevant role to play, despite the everincreasing level of automation and the standardization of working-procedures (Baines et al 2005). Quality managers focused their attention to human behaviour and try to analyse the causes of deviations from procedures where errors are detected [Miller \& Swain 1987). Safety experts included HF into accidents precursor analysis related to safety critical operations (Bosca et al 2015, Baldissone at al. 2018) and into ex-post events analysis (Comberti et al 2018). HF considerations are used in the area of work organization to reduce operational risks and improve task-time optimization(Lin et al. 2001, Leva et al 2013, Gerbec et al 2017). HF influence has been modelled and measured differently depending on the characteristics of each application. Human Performance modelling is a complex system, where behaviour, cognition, physiology and working condition deeply interact. However the topic of Human reliability analysis and modelling, was initially developed for safety critical industries such as nuclear and aviation and was not widely applied to manufacturing even where humans are still at the forefront of production process that are not completely automated. Automotive for instance is a sector where production systems are based on assembly lines that are required a cross interaction between highly automated workstations and highly trained human resources too. Different operators are needed to contribute towards the final products, which calls for different capabilities for analysing information, recalling items from memory, making decision etc. while performing time constrained tasks. An

Proceedings of the 29th European Safety and Reliability Conference.

Edited by Michael Beer and Enrico Zio

Copyright (c) 2019 European Safety and Reliability Association.

Published by Research Publishing, Singapore.

ISBN: 978-981-11-2724-3; doi:10.3850/978-981-11-2724-3_0688-cd 
empirical way to assess human performance, such as the reliability of individuals to perform specific tasks can be a very useful element in the process of allocating human resources to various workstations in an assembly line, as different workstations will present different elements of complexity, ultimately affecting the frequency of defects, human errors (Groth \& Mosleh 2012) and unsafe acts. The design of such a system requires an interaction between task complexity in terms of both mental and physical workload, and the assessment of the required human capabilities to cope with it.

\section{Human performance modelling in two industrial applications: the case studies}

The study is based on an observational, empirical approach aimed at existing human errors in tow different manufacturing contexts and locations.

\subsection{Case study 1:Packaging and assembly of electronic products}

The first case study was performed in the dispatching department of a company assembling large electronic products. The scope of the assessment was to model the issue and propose approaches to reduce and eliminate errors and variations in the end product. The company dispatches technology goods to national and international customers and the focus of the project was the assembly of goods for dispatch. Operators prepare the goods at workstations along conveyor lines, however at these conveyors inefficiencies and inaccuracies relating to human performance were identified. Two primary workstations were selected for inclusion in the dispatching unit based on their recorded error rates. Conditions vary and fluctuate at workstations, which may increase the probability of making mistakes, including the complexity and number of the activities, environmental conditions and the quality of the product. The modelling requires an understanding of both the salient characteristics of the human factors (cognitive aspects, physical capabilities and behavioural traits) and the impact of the features of the workstation on human nature (typology of activities, working load, environmental factors etc).

The focus is on the role of operator's capability to complete tasks and the means to reduce human errors whilst retraining product quality. Changes were proposed for the assembly lines at the dispatching stations, including changes in the procedures and training to employ an understanding of human performance and improvements to safety, with an overall beneficial impact on both productivity and quality.

\subsection{Case study 2: Heavy vehicle manufacturing}

The second case study was set in heavy vehicles assembly lines, which include a sequence of workstations. The level of robotic application is relatively low, most of the tasks are still manually performed As a consequence the impact of human performance on production efficiency is significant; human errors, expressed in term of defects and error of assembly, represent both an increase in cost and waste. The aim of this study was to deliver a Human Performance (HP) modelling capability able to identify areas of improvement in the industrial process so as to produce measurable impact on the rate of human errors. Within the scope of the work was the cooperation with the Management of the manufacturing plant, so as to deliver a practical operational model that could be applied by the plant managers themselves.

\section{Methodology and Conceptual Model Design} The methodology used to estimate Human Performance in the assembly line can be broken down into five steps (as it is showed in Fig. 1).

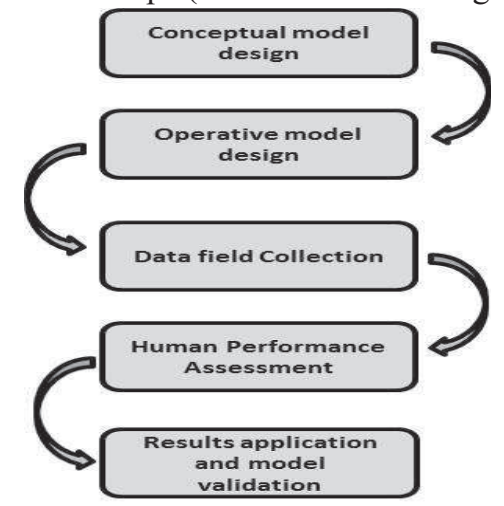

Fig. 1. Methodology for the development of the approach.

First step was focused on the "Conceptual Model" designing. This step began with understanding the variables having an influence on Workload and Human Capabilities. Those variables have been initially selected through a literature review balanced by an appraisal of the working conditions of the different workstation and a task analysis (Leva et al 2018) of the key activities of the workstations considered for the study in the assembly line. The second step consisted in characterizing the conceptual model to suit the actual empirical situation found in the case study. This process identified, with the support of task analysis method (Leva et al. 2009), the actual empirical data sources and or proxies to assess the variables of the conceptual model identified from the literature review, so as to be connected with one or more observable and measurable quantities. This process lead to a 
simplification of the initial conceptual model into a version applicable to the data availability and the needs expressed for the case study. DataField collection was dedicated to empirical measurements of all quantities defined in the operative model structure: results were used for Human Performance Assessment involving the assessment of the workload element together with operator's capabilities. The results obtained from the Data-Field collection campaign lead to the Human Performance (HP) assessment, and that is used to plan interventions on the human resources management of the assembly line. A validation period during which results, expressed in term of production efficiency, will be monitored would allow a validation of the proposed model.

\subsection{The Conceptual model}

The conceptual model is based on the Model developed by Rash (1982). In the Rasch model, the probability of a specified outcome (e.g. right/wrong results) is a logistic function of the difference between the person and item difficulty parameter. Let $\mathrm{X}_{\mathrm{ni}}$ be a dichotomous random variable with binary values where, for example, $\mathrm{X}_{\mathrm{ni}}=1$ denotes a correct response and an $\mathrm{X}_{\mathrm{ni}}=0$ an incorrect response to a given assessment item. In the Rasch model for dichotomous data, the probability of the outcome is given by the formula provided in equation (1):

$$
\operatorname{Pr}\left(X_{n i}=1\right)=e^{\beta_{n}-\delta_{i}} / 1+e^{\beta_{n}-\delta_{i}}
$$

where $\beta_{n}$ the ability of person $\mathrm{n}$ and $\delta_{i}$ the difficulty of item $i$.

The model needs to be radically enhanced to take into account an assessment of performance that is not dichotomous and feed into the interaction between two macro factors:

- Human Capability (HC): summarising the skills, training and experience of the people facing the tasks, representing a synthesis of their physical and cognitive abilities to verify whether or not they match the task requirements.

- Workload (WL) summarising the contribution of two main factors (Wickens 2017): "Mental Workload" (MW) and "Physical Workload" (PW), both associated to each activity identified and analysed in the assembly line.

\subsection{From a Conceptual model to an operational model}

To shift from a purely conceptual model to an operational one it was necessary to identify a set of actual observable and measurable quantities to estimate/assess the model variables. In addition to this, a common scale of evaluation for all quantities was adopted so as to allow a quantitative comparison between Human Capabilities (HC) against Workload (WL) requirements. The shift from a conceptual to an operational model implied the exclusion of the "Environmental factors" variable as it was the same for all the workstation and did not appear to have changes and or influence on the overall performance. The environmental conditions were in fact of good quality and therefore did not have an observable impact on performance, furthermore the environmental factors were approximately constant along the production line therefore their effect was not observable in this specific case study. With the exception of the environmental ones all the other variables identified in the conceptual model were matched by one or more observable quantities.

Each quantity had a different measurement-unit therefore to adopt a common scale, the indicators were scored according to calibrated Likert scales from 1to 10. Each Likert scale was calibrated according to the original unit measurements of the observable variables.

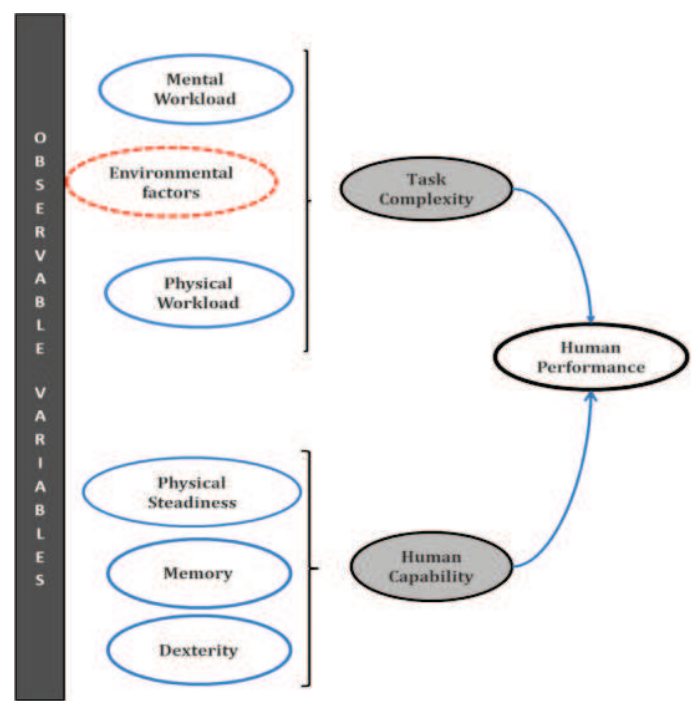

Fig. 2. Conceptual Model for Human Performance

\section{Operational model and data collection for Case study 1: Bayesian inference approach}

\subsection{Data collection and model application in case study 1}

In case study 1 it was not possible to run tests and collect observable data on Human capabilities for the workers involved in the project therefore members of staff who work closely with the workstations involved in the project and the control workstations were invited 
to complete questionnaires to assess their opinions relating to:

- The importance of skills at different workstations

- Skills rating of individual operators

- Job satisfaction / motivation

- Mental workload requirements

- Physical workload requirements

- Perceived task complexity

Two questionnaires were prepared with one for supervisors, group leaders and process engineers, and a second questionnaire for operators and technicians. Questionnaires were broken up in this fashion in order to capture observable variables from the supervisors/management and the individual subjective opinions of the operators. The questionnaires were completed by the employees of all eleven workstations and their supervisors leading to a total of 149 employees completing the questionnaire $(100 \%$ response rate). Participants were asked to rate their answers on a 10-point Likert Scale, with one meaning low and ten meaning high. As different duties and tasks require certain skills (e.g. manual skills, memory), practical training and underpinning knowledge, the questionnaire/observation protocol was designed to capture information relating to the aspects reported in Table 1.

Table 1: Aspects collected from Questionnaires

\begin{tabular}{|c|c|}
\hline Mental Workload & Worker Skills \\
\hline Requirements: & $\overline{\text { 1. Memory/ Recognition }}$ \\
\hline 1. Need to cope with pace & 2. Decision-making \\
\hline 2. Variance of product & 3. Coordination/communica \\
\hline $\begin{array}{l}\text { 4. Load due to quality of } \\
\text { coordination }\end{array}$ & $\begin{array}{l}\text { 4. Coping with pace } \\
\text { 5. Experience }\end{array}$ \\
\hline $\begin{array}{l}\text { 5. Requirement } \\
\text { training/experience }\end{array}$ & $\begin{array}{l}\text { 6. Dexterity / manual skills } \\
\text { 7. Physical resilience }\end{array}$ \\
\hline $\begin{array}{l}\text { 6. Human machine interface } \\
\text { (HMI) quality }\end{array}$ & 8. Adherence to procedure \\
\hline Physical Workload & Perceived Task \\
\hline Requirements & Complexity \\
\hline $\begin{array}{l}\text { 1. Ergonomic score (REBA } \\
\text { Assessment) }\end{array}$ & $\begin{array}{l}\text { 1. How mentally demanding } \\
\text { are the tasks }\end{array}$ \\
\hline $\begin{array}{l}\text { 2. Dexterity requirements / } \\
\text { manual skills }\end{array}$ & $\begin{array}{l}\text { 2. How physically } \\
\text { demanding are the tasks }\end{array}$ \\
\hline 3. Adherence to procedure & 3. How complex is this task \\
\hline 4. Reliance on automation. & perceived to be overall \\
\hline
\end{tabular}

The data set included not only questionnaires, but also observable variables derived from quality and productivity KPIs, focus groups on the task analysis, and video and photo recording and measurements on workstations and task (to measure the entire time of a task and number of subtasks when data about them was not available). The data is summarised in Table 2 .
Table 2: Error rate Dataset collected for each workstation

\begin{tabular}{|c|c|c|c|}
\hline $\begin{array}{l}\text { id } \\
\text { workstation }\end{array}$ & $\begin{array}{l}\text { skills } \\
\text { recorded }\end{array}$ & $\begin{array}{l}\text { task } \\
\text { complexity }\end{array}$ & $\begin{array}{l}\text { errors_on_- } \\
10000 \text { parts }\end{array}$ \\
\hline $1 \mathrm{Pod}$ & 6.45 & 7.4 & 1 \\
\hline 2 Conveyor & 6.45 & 7.28 & 15 \\
\hline 3 ControlA & 6.45 & 6.8 & 2 \\
\hline 4 ControlB & 6.45 & 6.8 & 7 \\
\hline 5 Control C & 7.18 & 8 & 2036 \\
\hline 6 ControlD & 7.23 & 9 & 4250 \\
\hline 7 ControlE & 7.09 & 7.57 & 70 \\
\hline 8 ControlF & 7.86 & 7.33 & 203 \\
\hline 9 ControlG & 5.33 & 6.33 & 681 \\
\hline $10 \mathrm{ControlH}$ & 6.27 & 6.4 & 190 \\
\hline 11 ControlI & 7.83 & 6.88 & 246 \\
\hline
\end{tabular}

The data was used for a regression model. The first part was used for an assessment of task complexity. The data gathered was evaluated on the basis of Task Complexity with a linear regression model:

$$
\begin{aligned}
& \text { TC }=\alpha * \text { Mem }+\beta * \operatorname{Rec}+\gamma * \text { Coord }+\delta * \text { Cope }+ \\
& \theta * \operatorname{Exp}+\mu * \operatorname{Res}+\rho * \text { Adh }
\end{aligned}
$$

Where TC is Task Complexity index, Mem is Requirements for Memory, Rec is requirements for Recognition skills, Coord is Coordinatin, Cope is requirements to Cope with pace, Exp is Experience, Res is Resilience and Adh is Adherence to procedure.

The Correlation matrix associated with the element used for the regression was used to validate the fact that the parameters were not correlated with each other and therefore were useful to represent diverse aspects. The model indicates that the parameters used to estimate task complexity in the linear regression are quite significant. They predict task complexity with a Standard error of 0.2991 on 36 degrees of freedom. The adjusted $\mathrm{R}$ squared obtained is 0.93996 and the F statistics on 36 Degrees of freedom is 96.52 , with a $\mathrm{p}$ value of $2.2 \mathrm{e}-16$. Therefore the linear regression model to estimate task complexity seems to deliver significant results.

For the second part of the model, an estimation of the error occurrence of each workstation considering task complexity and operator capability was conducted. The use of the Rasch model with the dataset gathered was not possible as for the Rasch model the output needed to be a binary success or failure for each individual task. This was a type of data, which was not able to be collected for case study 2. Due to this, a generalised linear regression with a Poisson 
model, which was still based on the assumption that Human Performance can be represented as directly dependent from two macro-factors of task complexity and human capability, was used (see formula 3 ).

$\lambda_{i}=e^{\beta_{0}+\beta_{1} x_{1}-\beta_{2} x_{2}+\varepsilon_{i}}=e^{\eta_{i}} \rightarrow \log \lambda_{i}=\eta_{i}$

where $\lambda_{i}$ is the amount of error recorded, $x_{1}$ is task complexity and $\mathrm{x}_{2}$ is operator skill level/capability. The results obtained in $\mathrm{R}$ suggest that both elements are significant in predicting error occurrence, as shown in Fig. 3. A likelihood ratio test also confirmed the meaningfulness of the significance for the parameter chosen for estimating the error rate with this model.

glm(formula $=$ errorateSerrors_on_10000parts $\sim$ errorate\$average.skills + (erroratestask. complexity), family = poisson, data = errorate)

\begin{tabular}{|c|c|c|c|c|}
\hline Min & 1 & dian & 30 & \\
\hline-31.533 & -21.480 & -1.975 & 8.522 & 31.609 \\
\hline
\end{tabular}

Coefficients:

$\begin{array}{lrrrrr} & \text { Estimate Std. Error } z \text { value } \operatorname{Pr}(>|z|) \\ \text { (Intercept) } & -2.41163 & 0.19002 & -12.69 & <2 \mathrm{e}-16 * * * \\ \text { errorateSaverage. skills } & -0.47110 & 0.03457 & -13.63 & <2 \mathrm{e}-16 * * * \\ \text { errorateStask. complexity } & 1.57751 & 0.01710 & 92.24 & <2 \mathrm{e}-16 * * *\end{array}$

Fig. 3. Excerpt of R code used for the Regression model

\subsection{Bayesian approach for case study 1}

Case study 2 presented a more limited data with estimates of skill variables obtained using subjective rating. Therefore the model application could be improved with a more extensive data collection campaign and a more objective estimation for skill rating. Another attempt was to perform a Bayesian inference by including prior information on the parameters of interests that were presented in equation (3). In this context we used:

$$
\beta \sim N_{3}\left(b_{0}, B_{0}^{-1}\right)
$$

where $b_{0}$ is the vector of means for the explanatory variables and $\mathrm{B}_{0}{ }^{-1}$ is the $\mathrm{k} \times \mathrm{k}$ precision matrix, i.e., the inverse of a variance/covariance matrix. In this context we used a flat 3-dimensional distribution centred at 0 with diagonal variance/covariance matrix whose entries are equal to 9. Therefore the Prior distribution chose was not very informative.

The target of our analysis is the posterior distribution of the parameters given the data which has been estimated using MCMC algorithm with 10000 iterations with 1000 burnin iterations.

The results in $\mathrm{R}$ (obtained using the Zelig package) are in agreement with those obtained by maximum likelihood estimation used in the model (see Fig.3) and are reported in Fig. 4.

Fig. 4. Excerpt of R code used for the Bayesian inference

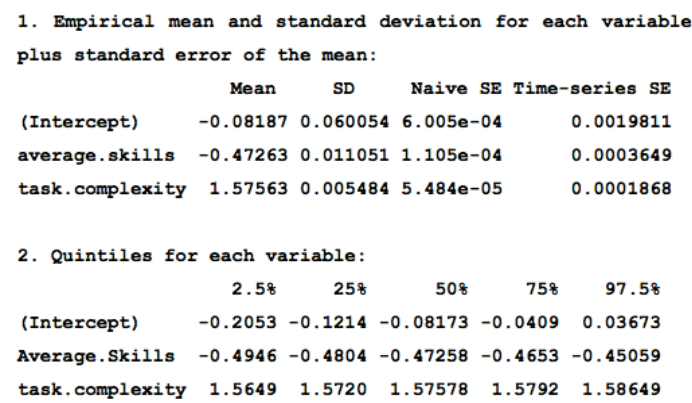

5. Operational model and data collection for Case study 2:

Case study 2 refers to workstations in heavy vehicle manufacturing. The variables were selected thanks to a participatory approach focusing on process modelling and screening of available performance data, that involved both academic and industry professionals operating in the various management areas involved: Safety, Work Analysis, Quality, Work Organization.

The observable variables selected were measured both in numerical and qualitative scales.

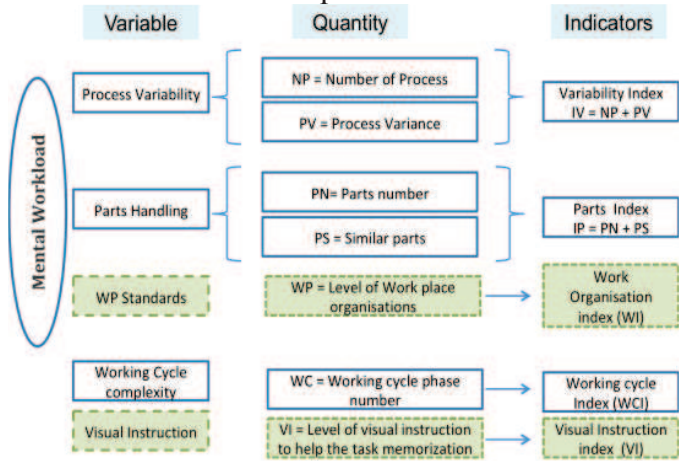

Fig. 5: Mental Workload Operational model.

To allow comparison between variables with different nature and scale, all the variables were harmonized in a common numerical scale. The Task Complexity factor was estimated trough the assessment of the observable variables that are related to Mental Work Load (Fig.5) and to Physical workload (Fig. 6). 


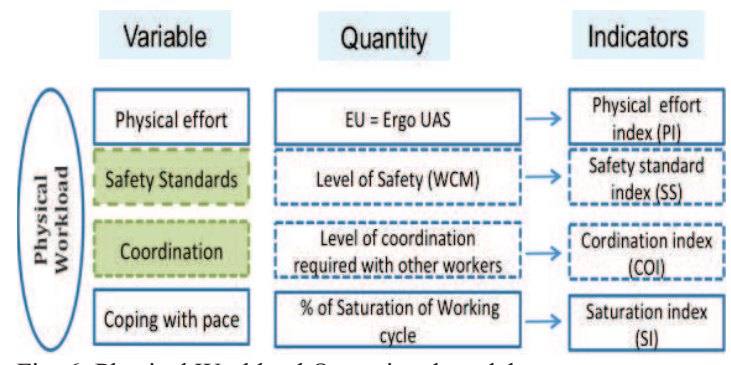

Fig. 6: Physical Workload Operational model

The data collected to operationalized a human capability model were estimated using a battery of tests performed as the so called "ability corners" and used to estimate an operational model for human capabilities (see Fig. 7).

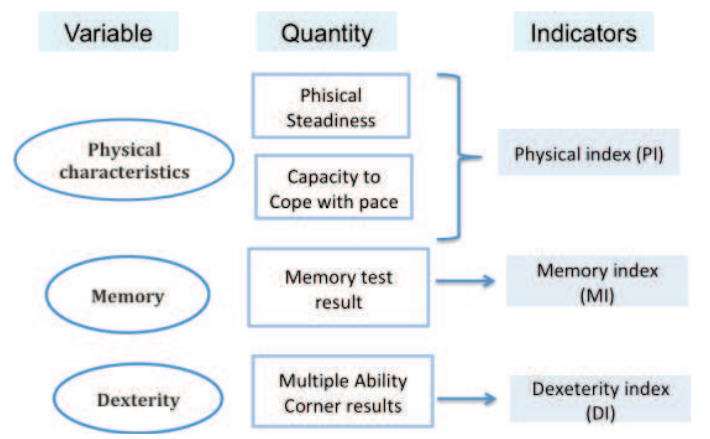

Fig. 7: Human Capabilities Operational model.

The Human Capability (HC) model represents the total amount of resources that a worker potentially can provide to perform a given task.

According to the kind of tasks involved into the assembly line, the $\mathrm{HC}$ conceptual model identified 3 set of measurable capabilities: Manual skills (Dexterity), Memory and Physical skill. In order to assess these skills a set of empirical tests were designed.

The key conditions considered for the test design process were the followings:

A. The tests have to represents or simulate frequents operations close to the ones performed in the assembly line.

B. The tests have to be performed by workers during the working activity, as a consequence the time requested to perform them needs to be below 10 minutes.

Considering the above conditions four test were defined:

1. Memory test: sequences of geometric schemes were shown to the worker for few second. The worker was then asked to replicate them on a piece of paper. During this test the time to complete the task and its accuracy were recorded.
2. Precision test: it consists in moving an iron circle along a not linear contour without touching the line. This test is related to the manual precision required in many tasks. During this test the time to complete the path and the number of errors were record-ed.

3. Coordination test. In this test the worker is required to use both hands to perform simple actions. Time and precision of coordinate movements were recorded.

4. Methodology test. During this test the worker have to decide and to complete a set of simple assembly steps with small parts. Time and errors were recorded

The Human Capability results of each worker were considered recording the time spent to complete all tests and the number of errors done. The HC assessment campaign with the tests involved directly 50 workers employed in the selected assembly line. The tests were planned so as to minimize the impact on the working activity of the assembly line itself and the average time of execution was between 7-9 minutes. To perform the tests each worker was given a short break, for the time strictly necessary, and replaced by a substitute. This configuration allowed the tests to be repeated 3 times during the whole shift for all the workers. All test results showed a good discrimination of workers skills highlighting a wide range of variation in performances. The $\mathrm{HC}$ indicators were all reported in a numerical scale 1-10 in relation to test results. The test measures 2 quantities: the amount of time spent to complete the test and the number of errors committed during its execution. The two quantities were combined in a single index as reported in equation (5). Considering the results of each individual skill test, time and errors observed in the text were linearly combined in a common quantity named "Modified Time" (MT) according to the following equation:

$$
\mathrm{MT}=\text { Time }[\mathrm{s}]+\text { Errors } \times 3[\mathrm{~s}]
$$

The Task complexity model results in terms of indices harmonised in a Likert scale and the Human Capability models results where compared using a matching index matrix that compared the required skills for each workstations with the harmonised recorded skillsets of each worker. This activity involved 150 workers operating in 4 assembly lines.

The Human Performance assessment was defined according to the scheme proposed in the Conceptual model (Figure 3) and in compliance with the operational evaluation process defined for $\mathrm{HC}$ and WL. The HP calculation therefore is outlined as follow (see Figure 10): for each 
possible matching worker/workstation the combination of the $3 \mathrm{HC}$ index with 4 Work Load index lead to an overall matching index reported in equation (5):

$$
\mathrm{HC}_{\text {worker }}-\mathrm{WL}_{\text {workingplace }}=\mathrm{HP}
$$

The Matching-index assesses the level of adequacy of human capability to the workload determined for each workstation.

The total number of workstations considered was approximately 23 .

The application of this model implied the calculation of 50 Human Capability profiles and 23 Task Complexity profiles.

The HP calculation was done according the scheme reported in Fig 8.

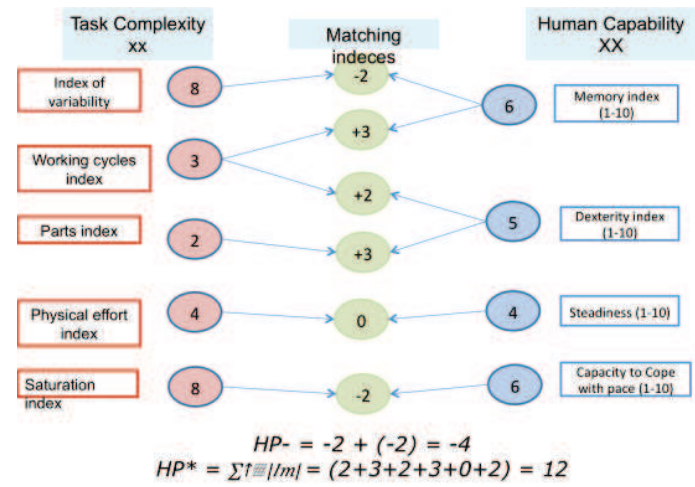

Fig. 8: Human performance assessment operational model.

This scheme of calculation is based on a linear comparison between the Human capability index and the Task complexity index "HC-index - TCindex" and leads to the definition of 6 matching indexes. Two Human Performance index can be defined:

- $\quad$ HP- : represents the sum of all negatives matching index.

- HP*: represents the sum of all absolute values of matching index.

The assessment for each assembly line of HPand $\mathrm{HP}^{*}$ will allows a quantitative calculation of the potential Human Performance related to the matching workers-working places as an optimization algorithm to allow a matrix of potential combination with resulting clustering. Minimizing HP- and HP* implies the optimization of the distribution of the workers in the available workstations on the basis of the human capability scoring assessed for each worker and the task complexity associated to each workstation. This matching index is a predictor of human performance, as the lower the value of HPminus the higher is the probability of human error for that combination. On the basis of this systematic assessment of HPminus and HPplus, for all the possible combination workers/workstation a matrix of matching combination is defined. Fig. 9 summarises the results of this approach showing, as an ex-ample the matrix of combinations obtained for 5 workstations and 25 workers (with all their relative HP assessment index). The score of the 25 workers are reported for each workstation in a decreasing order (the workers are in the upper row, and the HP index in the lower row).

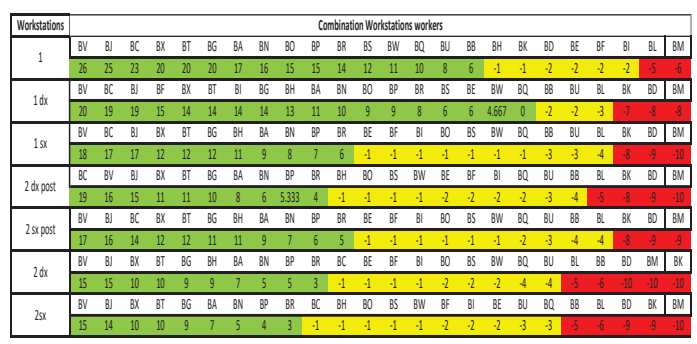

Fig 9 Matching matrix

An optimization algorithm was then set up in $\mathrm{R}$ to define a heat maps clustering workstations and workers combination as represented in Fig.10.

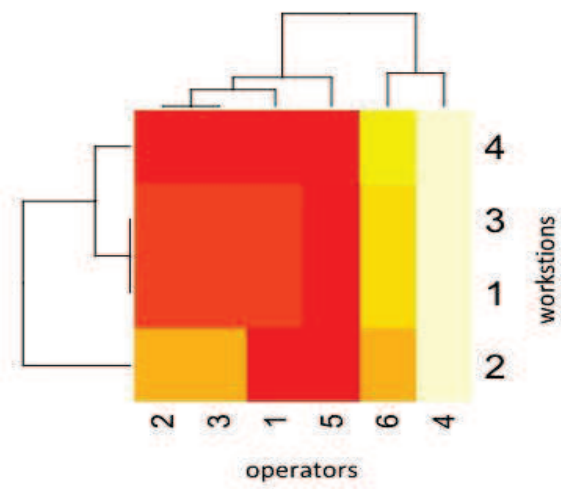

Fig 10 Heat map in R for Workstations and workers HP combinations

\section{Conclusions And Way Forward}

The data formed the basis of an empirically based, cross-verified model of human performance that can be used to provide objective feedback to users increasing their awareness of risks related to their own human characteristics and impact the design of safety critical systems and current approaches for vocational training. For the manufacturing facilities involved in the project, further developments may include engaging operators in all elements of a process, induction testing to match operator's capabilities to task most suited to them and orientation of workstations to facilitate operators considering human error and ergonomics principles. Human error in the manufacturing facility prior to an intervention or 
examination of human performance contributed to the occurrence of a large number of errors resulting in financial costs and productivity losses for the organisation. The reorientation of work practices at work-stations, considering the role of human error and ergonomic principles, has allowed for a reduction in the incidence of human related errors across the workstations examined. The model developed was declined as an matching index formulation and or as a Poisson generalised linear regression. However in both cases it stems formt he same underpinnign theoretical assumption of having a comparable assessment for task compelxity and corresponding human capbilities as a predictor of human performance (or error rate). The results suggests that both task complexity and operator's skill are valid predictors of error occurrence in a workstation. It is maybe also possible that while task complexity increases a corresponding linear increase in worker skills and capability is not able to sufficiently compensate for the increased complexity. The model developed int his paper has been named "Task Execution Reliability Model" (TERM) and further declinations and applications for it will be explored.

\section{References}

Baines, T.S., Asch, R., Hadfield, L., Mason, J.P., Fletcher, S., Kay, J.M.: Towards a theoretical framework for human performance modelling within manufacturing systems design. Simulation Modelling Practice and Theory, 13(6), 451--524 (2005).DOI: 10.1016/j.simpat.2005.01.003

Baldissone, G., Comberti, L., Bosca, S., Murè, S. (2018): The analysis and management of unsafe acts and unsafe conditions. Data collection and analysis. Safety Science. In press.

Bosca, S., Comberti, L., Baldissone, G., Demichela, M., Murè, S.: Occupational Accident precursors management systems. In: Proceedings of the 49th ESReDA Seminar: Brussels, (2015).

Comberti, L., Leva, M. C., Demichela, M., Desideri, S., Baldissone, G., \& Modaffari, F. (2018,). An Empirical Approach to Workload and Human Capability Assessment in a Manufacturing Plant. In International Symposium on Human Mental Workload: Models and Applications (pp. 180201). Springer, Cham.

Gerbec, Marko, Nora Balfe, Maria Chiara Leva, Steve Prast, and Micaela Demichela. (2017) "Design of procedures for rare, new or complex processes: Part 1-An iterative risk-based approach and case study." Safety science $100: 195-202$.

Harris, D. (2006). The influence of human factors on operational efficiency. Aircraft Engineering and Aerospace Technology, 78(1), pp.20-25.

Hong, K., Nagaraja, R., Iovenitti, P., Dunn, M.: A socio-technical Approach to Achieve Zero Defect
Manufacturing of Complex Manual Assembly. Human Factor and Ergonomics in Manufacturing 17 (2), 137--148 (2007). DOI: 10.1002/hfm.20068.

Jo, S., Myung, R. and Yoon, D. (2012). Quantitative prediction of mental workload with the ACT-R cognitive architecture. International Journal of Industrial Ergonomics, 42(4), pp.359-370.

Karl, R. and Karl, M. (2012). Adverse Events: Root Causes and Latent Factors. Surgical Clinics of North America, 92(1), pp.89-100.

Kostina, M., Karaulova, T., Sahno, J. and Maleki, M. (2012). Reliability estimation for manufacturing processes. Journal of Achievements in Materials and Manufacturing Engineering

Leva, M. C., Caimo, A., Duane, R., Demichela, M., \& Comberti, L. (2018). Task Complexity, and Operators' Capabilities as Predictor of Human Error: Modeling Framework and an Example of Application in Haugen, S., Barros, A., van Gulijk, C., Kongsvik, T., \& Vinnem, J. E. (Eds.). (2018). Safety and Reliability-Safe Societies in a Changing World: Proceedings of ESREL 2018, June 17-21, Trondheim, Norway. CRC Press.

Leva M, Bermudez Angel C, Plot E, Gattuso M (2013). When the Human Factor is at the core of the safety barrier. CHEMICAL ENGINEERING TRANSACTIONS, vol. 33, p. 439-444.

Leva, Maria Chiara, Alison Mragaret Kay, Fabio Mattei, Tom Kontogiannis, Massimiliano De Ambroggi, and Sam Cromie. (2009) "A dynamic task representation method for a virtual reality application." In International Conference on Engineering Psychology and Cognitive Ergonomics, pp. 32-42. Springer,

Mijovic B. 2017. How hard is walking. blog https://blog.mbraintrain.com/@boggisha (last accessed 20/09/2017)

Miller, C. and Parasuraman, R. (2007). Designing for Flexible Interaction Between Humans and Automation: Delegation Interfaces for Supervisory Control. Human Factors, 49(1), pp.57-75

Miller, D.P., Swain, A.D.: Human error and human reliability. Handbook Human Factor, WileyInterscience, New York.(1987)

Morgeson, F., DeRue, D. and Karam, E. (2010). Leadership in Teams: A Functional Approach to Understanding Leadership Structures and Processes. Journal of Management, 36(1), pp.5-39.

Rasch G. (1980) Probabilistic Model for some Intelligence and Attainment Tests. University of Chicago Press. Chicago.

Sheridan, T. (2008). Risk, Human Error, and System Resilience: Fundamental Ideas. Human Factors: The Journal of the Human Factors and Ergonomics Society, 50(3).

Wickens, C. D. (2017): Mental workload: assessment, prediction and consequences. In International Symposium on Human Mental Workload: Models and Applications. pp. 18--29. Springer, Cham 